\title{
OS CORPOS DE ARENITOS PRAIAIS QUE SUSTENTAM O FORTE DOS REIS MAGOS, PRINCIPAL CONSTRUÇÃO HISTÓRICA DA CIDADE DE NATAL-RN.
}

\author{
BEACHROCKS SANDY BODIES THAT SUPPORT THE REIS MAGOS' FORT, MAIN \\ HISTORICAL CONSTRUCTION OF THE CITY OF NATAL-RN.
}

\author{
Matheus Lisboa Nobre da SILVA ${ }^{1}$; Tarsila Barbosa DANTAS ${ }^{1}$; Marcos Antonio Leite do \\ NASCIMENTO ${ }^{2}$; Marcela Marques VIEIRA ${ }^{2}$ \\ (1) Centro de Ciências Exatas e da Terra, Universidade Federal do Rio Grande do Norte. \\ Endereço eletrônico: nobre.mt@gmail.com, tarsilabdantas@hotmail.com \\ (2) Departamento de Geologia, Centro de Ciências Exatas e da Terra, Universidade Federal do Rio Grande do Norte, Natal, RN. \\ Endereços eletrônicos: marcos@geologia.ufrn.br, marcela@geologia.ufrn.br
}

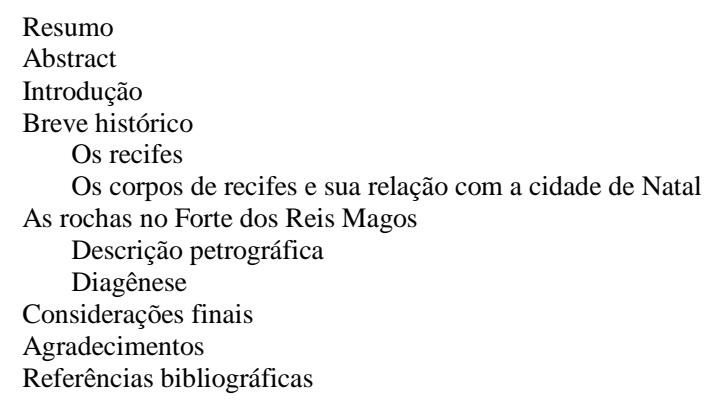

\begin{abstract}
RESUMO - Ao longo de toda a história do homem, as rochas se fizeram presente. Inicialmente, utilizadas como instrumentos de caça, hoje esse elemento da geodiversidade do planeta tem importância econômica, funcional e cultural intrínsecos com o cotidiano da sociedade. Em Natal, capital do Rio Grande do Norte, a percepção do possível uso das rochas locais para o desenvolvimento da cidade se iniciou ainda no processo de construção da primeira edificação local que é o Forte dos Reis Magos. Por muitos anos um ponto de importância para a manutenção do domínio português na região Norte e Nordeste do Brasil, o Forte dos Reis Magos possui quase 400 anos de história em suas paredes erguidas com os arenitos calcíferos encontrados em seus arredores, que já foram objetos de estudo desde o início do século XX. O trabalho aqui apresentado foi realizado a partir de trabalhos arqueológicos conduzidos pelo IPHAN e se propõe a analisar as rochas utilizadas na construção do Forte, e assim mostrando a forte relação entre a geodiversidade, a cidade e as ciências.
\end{abstract}

Palavras-chave: geodiversidade, Forte dos Reis Magos, arenitos praiais.

\begin{abstract}
Throughout the history of mankind, the rocks have always been present. Initially used as hunting tools, this element of the geodiversity of the planet has nowadays economic, functional and cultural importance intrinsic to the daily life of society. In Natal, capital of Rio Grande do Norte State (Brazil), the perception of the possible use of local rocks in the development of the city started during the process of construction of its first building Reis Magos Fort. For many years an important point of the Portuguese domain in the North and Northeast of Brazil, the Reis Magos Fort has nearly 400 years of history. Its walls were built with calciferous sandstones (beachrocks) found in its surroundings, which have been studied from the early twentieth century. The work presented here was conducted by IPHAN after archaeological work and aims to analyze the rocks used in the construction of the fort and also show the strong relationship between geodiversity the city and the sciences.
\end{abstract}

Keywords: geodiversity, Reis Magos' Fort, beachrocks.

\section{INTRODUÇÃ̃o}

O Forte dos Reis Magos está localizado na desembocadura do Rio Potengi, em área de grande importância histórica, cultural e ambiental para a cidade de Natal. Sua construção teve início no século XVI, mas a conclusão da estrutura hoje remanescente só se deu em 1628. A área adjacente ao Forte é constantemente frequentada por banhistas, natalenses e turistas, que buscam o banho nas piscinas naturais da Praia do Forte ou a cultura com a visita ao monumento.

Apesar de ser por vezes nomeado como Fortaleza, o principal monumento histórico da capital potiguar é caracterizado como um Forte.
Cascudo (1999) explica que devido à construção natalense possuir apenas uma bateria de artilharia, esta seria a nomenclatura correta, que é neste trabalho adotada.

O Forte dos Reis Magos é um elemento imponente na paisagem de Natal e esteve sempre associado ao cotidiano da cidade, sendo hoje um dos principais cartões postais locais. É, portanto, um elemento de rica história cultural, mas também natural.

Dentro da escrita desta história, está a geologia (com os elementos da geodiversidade), visto que esta ciência contribui para o desenvolvimento científico e tecnológico da 
sociedade moderna como mostram Del Lama et al. (2015). Para esses autores, o conhecimento geológico é uma ferramenta excepcional no processo de entendimento da história do próprio homem e na conservação da história do planeta e da sociedade em si.

A região onde se encontra o Forte dos Reis Magos é compreendida pela Zona de Proteção Ambiental ZPA - 07, tendo ainda inúmeras feições geológico-ambientais distintas tais como: arrecifes (ou recifes de arenito), zona de praia (Praia do Forte), cordões dunares, estuário, vegetação de mangue entre outras (Natal, 2010). Dentre as feições geológicas na área, a de maior destaque é a dos corpos de arenitos praiais (beachrocks) que se estendem por mais de três quilômetros, de direção aproximadamente N-S, desde a Praia dos Artistas até o local onde o Forte foi erguido, de forma paralela à linha de costa atual e que podem ser separados em dois corpos lineares (Figura 1). Estes arenitos praiais são rochas sedimentares geradas pela compactação e/ou cimentação de grãos provenientes do retrabalhamento de outras litologias mais antigas e representam antigas linhas de costa. Barreto et al. (2000) dataram vários arenitos praiais do Rio Grande do Norte e verificaram que a formação dessas rochas holocênicas ocorreu desde 7.000 anos A.P em todo o estado, sendo os encontrados no litoral natalense mais recentes.

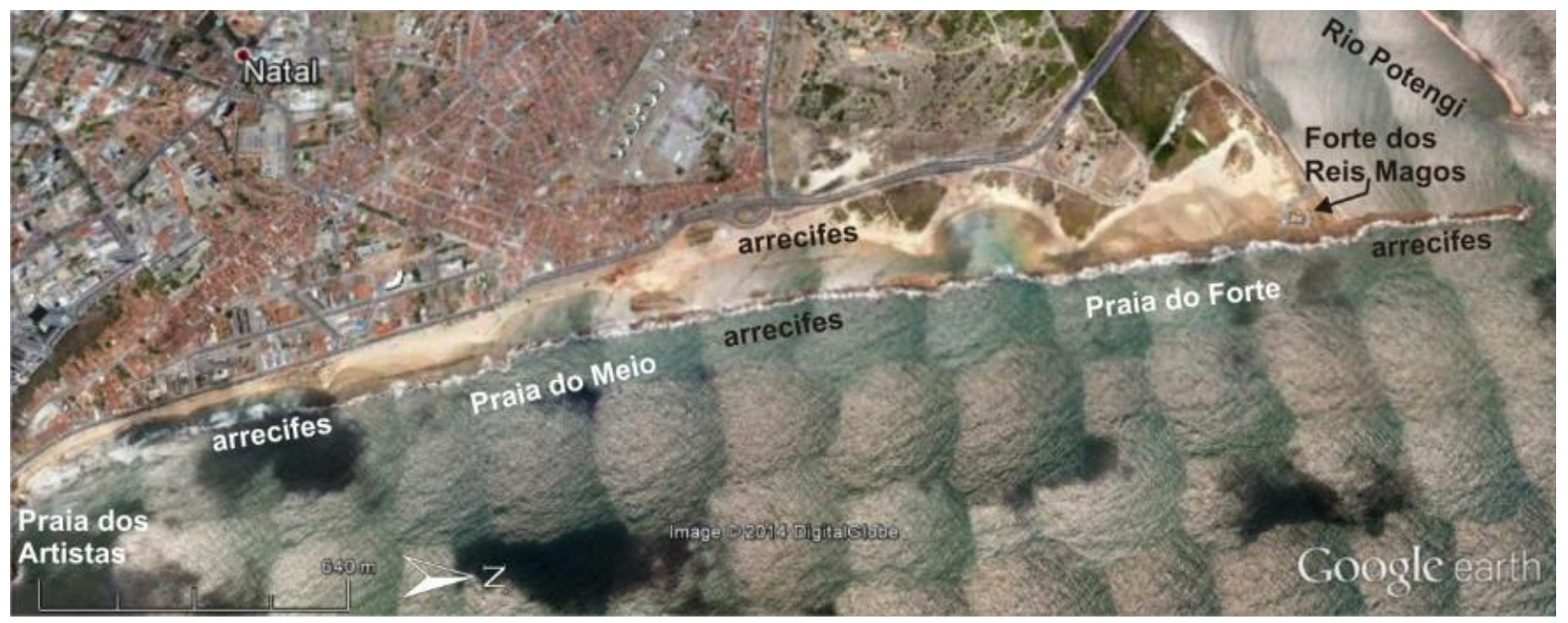

Figura 1 - Visão geral da região compreendida entre a Praia dos Artistas e o Forte dos Reis Magos, onde afloram dois corpos lineares de arrecifes. Fonte: Google Earth (imagem de janeiro/2013).

\section{BREVE HISTÓRICO}

\section{Os recifes}

Com história de mais de quatro séculos em suas paredes, o Forte dos Reis Magos se confunde com a própria cidade de Natal, sendo um de seus monumentos e ícones. A sua posição estratégica foi extremamente impor-tante na colonização do Nordeste do país, em especial da então capitania do Rio Grande, mas só foi possibilitada pela existência de longos corpos de arenitos praiais (popularmente conhecidos na área por recifes ou arrecifes) na região, que propiciaram base sólida para a fortificação.

Estes corpos formados por arenitos e conglomerados possuem íntima relação com a paisagem, as construções históricas e cultura locais.

De acordo com Barreto et al. (2000) a palavra "arrecife" tem etimologia associada ao árabe "árraçif", cujo significado é calçada, caminho ou estrada pavimentada, vinculada à forma arcaica de recife. Tratam-se de grãos de areias cimentados por carbonato de cálcio, contudo é muitas vezes confundido pela população com o termo "recife de coral", formado a partir do crescimento de grande diversidade de organismos coloniais (corais hermatípicos e algas calcárias) sobre as rochas.

Os recifes de arenito são frequentes na costa do Nordeste brasileiro, dispostos normalmente paralelos à costa e apresentando maiores extensões junto a desembocaduras de rios, representando traços morfológicos e feições características do litoral Nordestino, a exemplo do que mostra o trabalho de Ferreira Júnior et al. (2011) no estado de Pernambuco 
Os corpos de recifes e sua relação com a cidade de natal

As faixas de recifes de arenitos estão constantemente presentes na zona costeira do Rio Grande do Norte, principalmente na região litorânea oriental do estado.

$\mathrm{Na}$ região onde ocorre o Forte dos Reis Magos, especificamente os recifes encontrados na faixa entre as praias dos Artistas e do Forte, eles foram identificados como parte fundamental da paisagem ainda no século XVII, quando, em pleno domínio holandês no nordeste brasileiro, o pintor Frans Post registrou em sua obra "Fort Ceulen" (Figura 2), o Forte dos Reis Magos e os arenitos em suas proximidades, o que demonstra a presença marcante desses corpos areníticos na área.

Fort Ceulen foi o nome dado ao Forte durante a ocupação holandesa entre 1633 e 1654.

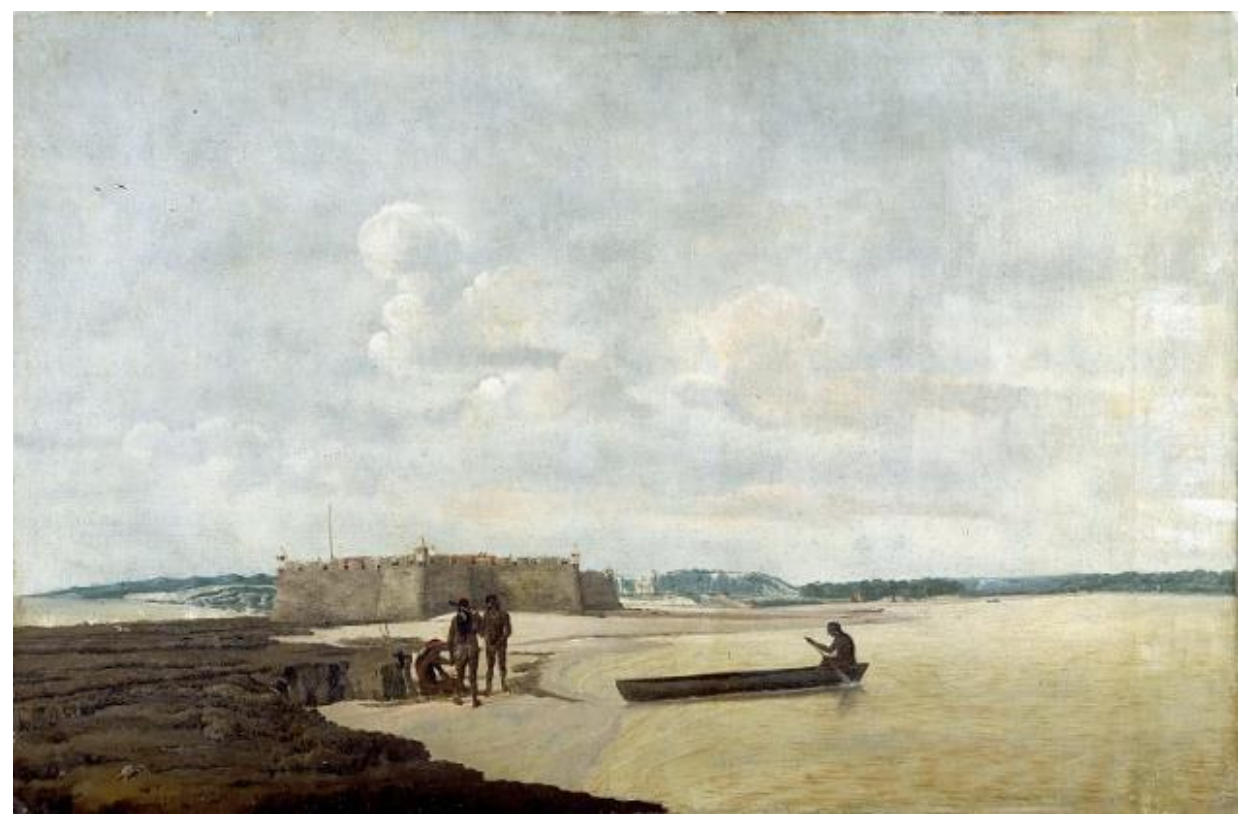

Figura 2 - Obra conhecida como "Fort Ceulen" (1638), do pintor holandês Frans Post, mostrando, ao fundo, o Forte dos Reis Magos, os arrecifes (lado esquerdo da foto) e uma representação do povo Potiguara que habitava a região. Fonte: site da www.gallerix.ru, acessado em 10/06/2015.

Os primeiros registros sobre os recifes da cidade de Natal foram feitos entre a última década do século XIX e os primeiros anos do século XX. Branner \& Gilman (1900) consideram os recifes potiguares como verdadeiras obras de arte [...seeing the one at Rio Grande do Norte, would find it difficult to believe that it was not a work of art - página 342]. Branner \& Gilman (1900, tradução de Alfredo de Carvalho, com permissão dos autores) identificaram "formações fantásticas, cheias de pontas e arestas agudas, [...] e alguns pequenos fragmentos chatos, semelhantes a cogumelos ou guarda-chuvas abertos" nos recifes da Praia do Forte. Eles também fazem menção à linearidade praticamente constante do recife. Ainda neste trabalho, os autores já mencionam a existência de duas linhas de recifes [É digno de menção que, apezar da direcção desta notável rocha variar um pouco, no conjuncto Ella é quase recta; outra feição assaz característica consiste em parecer ser acompanhada em parte da sua extensão por outro recife interno que vae immergir junto ao principal - página 39] e que o recife maior se mostra mais largo, principalmente no Forte dos Reis Magos, mas isso devendo a possível união com o recife menor [... que a parte mais ampla deste (recife) é onde está construído o forte dos Reis Magos, e esta largura desusada resulta evidentemente da reunião dos recifes neste ponto - página 39].

Em 1904, Branner mostrou que a face dos arenitos que compõem os recifes inclina-se suavemente para o oceano (no caso em média de $5^{\circ}$ ) e que se encontra coberta por corais e outros espécimes Algae, também encontradas no registro geológico em amostras das rochas do local. Este autor volta a mencionar a existência de duas linhas paralelas de corpos areníticos, agora expondo tal observação por meio de um mapa (Figura 3a), como também 
foi apresentado por Oliveira (1978, Figura $3 b)$, classificando os recifes em "recife interno e externo", sendo o interno posicionado mais próximo ao continente -

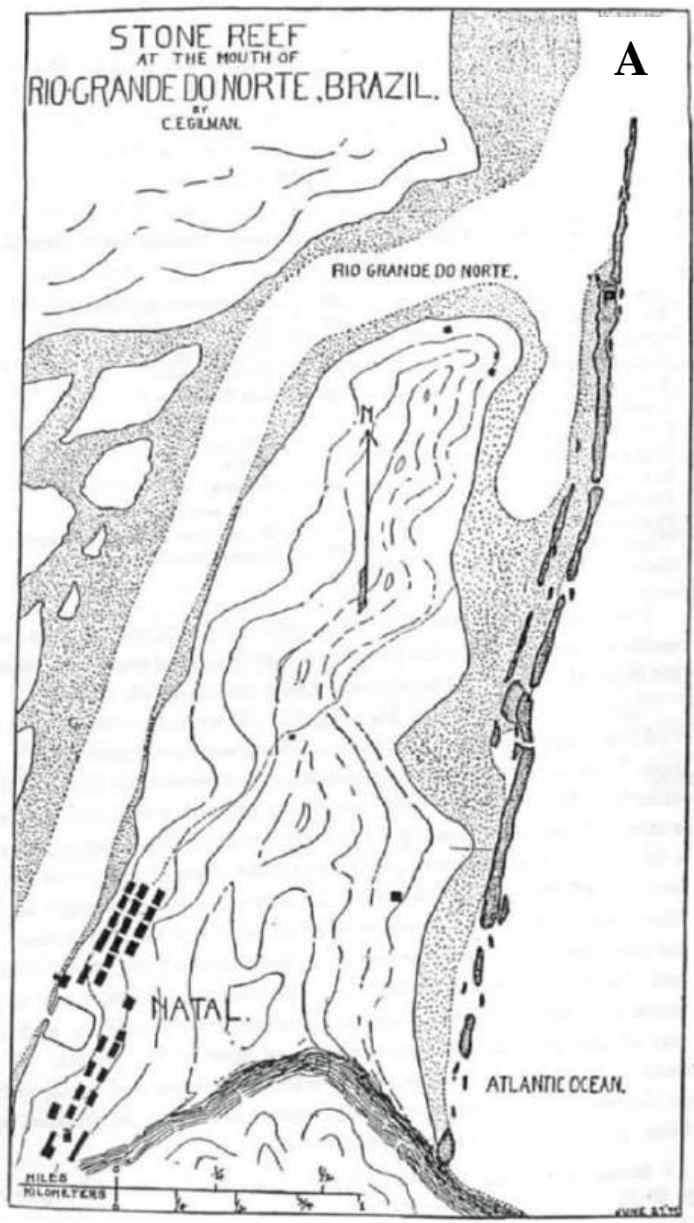

menos contínuo e mais curto que o externo que fica mais distante do continente e que se apresenta de forma mais contínua e extensa (Figuras 4 e 5).

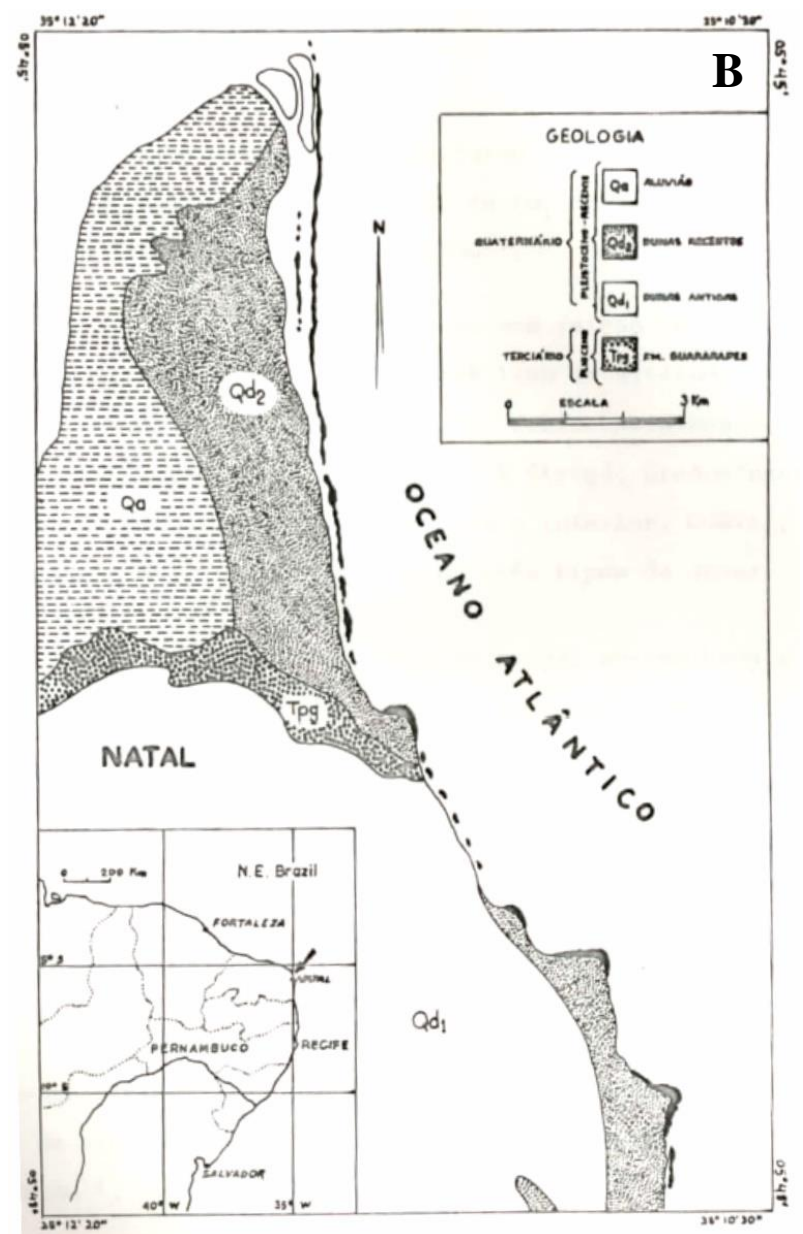

Figura 3 - Registro histórico de alguns dos primeiros mapas de ocorrências de recifes do litoral oriental do Rio Grande do Norte, com destaque para a região entre as praias dos Artistas e do Forte. Notar a presença de duas linhas de rochas, uma mais interna e menos contínua (mais próxima do continente) e outra mais externa e contínua (mais distante do continente). Fonte: (a) Branner (1904) e (b) Oliveira (1978).

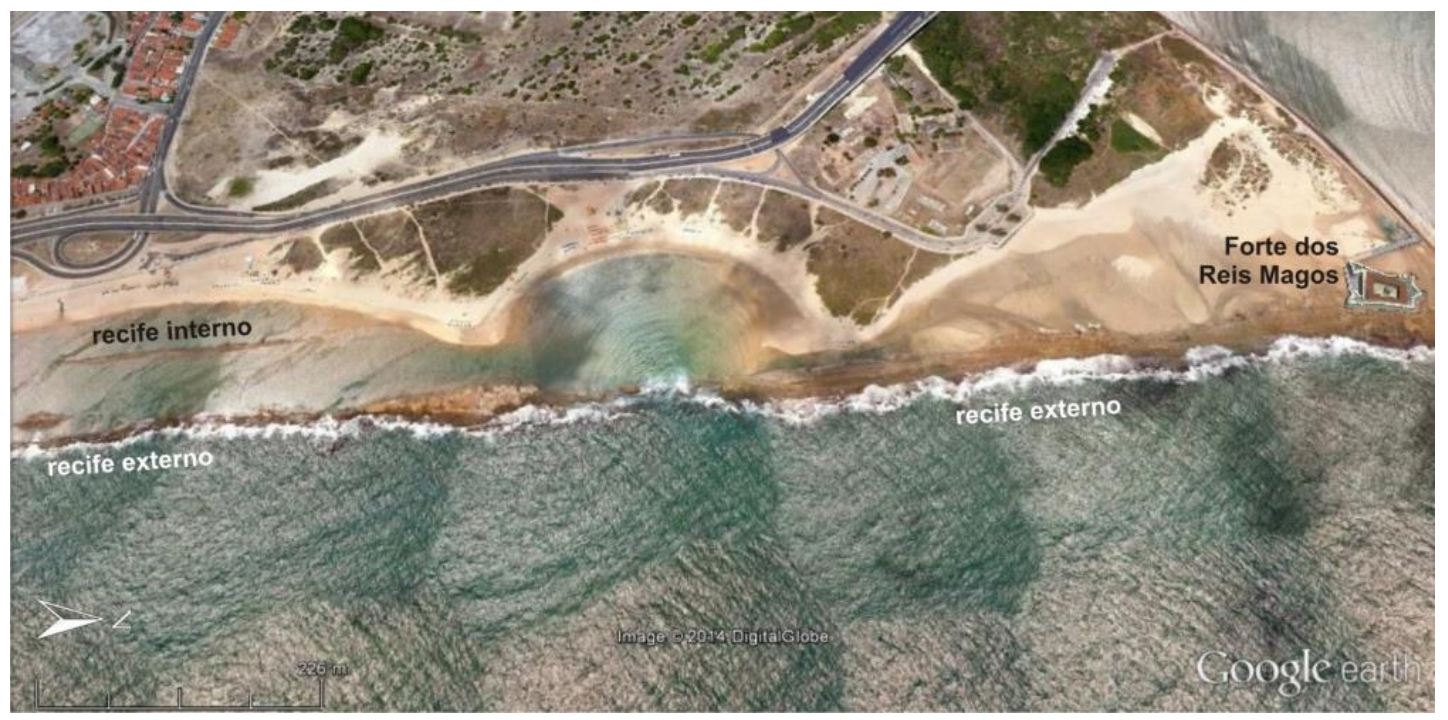

Figura 4 - Visão geral da região litorânea nas proximidades do Forte dos Reis Magos, com destaque para os dois corpos lineares de recifes, descritos por Branner (1904) como interno e externo. Fonte: Google Earth (imagem de janeiro/2013). 


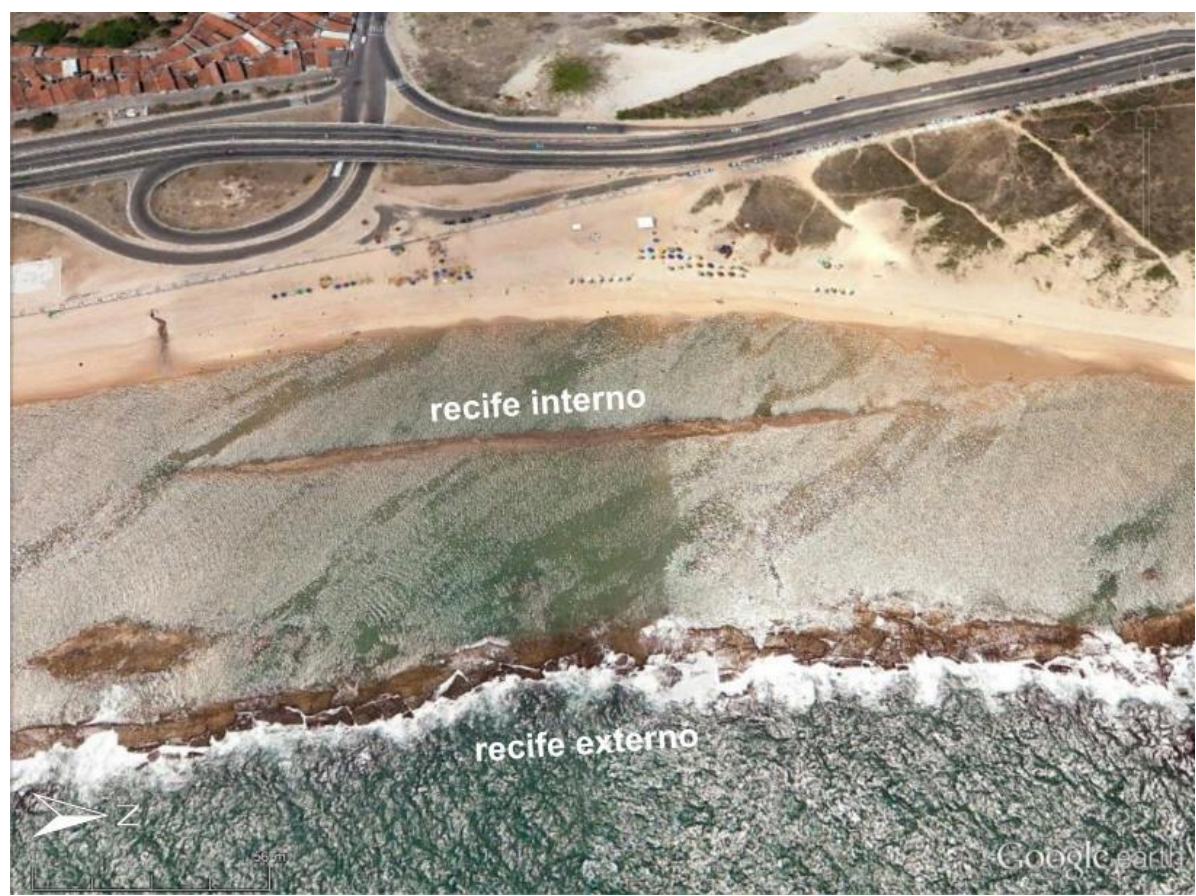

Figura 5 - Detalhe da região de ocorrência, de parte, do recife interno parcialmente imerso pelas águas. Fonte: Google Earth (imagem de janeiro/2013).

O recife interno é constituído por rochas semelhantes à do externo, mas não tão maciças. Branner (1904) sugeriu que a formação dessas rochas pudesse estar relacionada à percolação de águas pluviais saturadas em carbonato de cálcio provindas do continente. Segundo ele, essas águas se tornariam ricas em carbonato após passar por regiões calcárias. E, essa água saturada com respeito a carbonato de cálcio, ao entrar em contato com água marinha, precipitaria o carbonato de cálcio em forma de

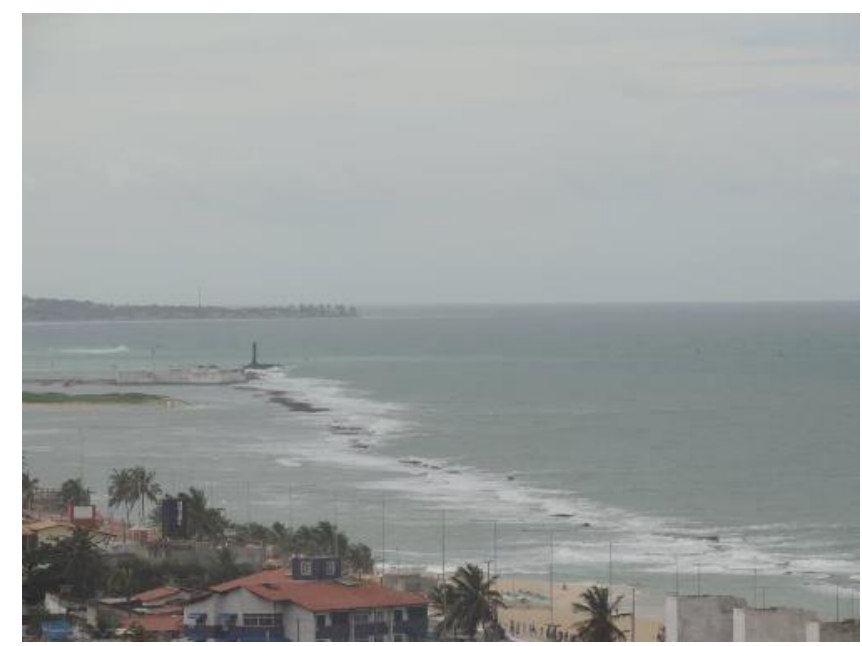

cimento, dando origem aos recifes (stone reef, segundo Branner, 1904).

Em fotos recentes (11 e 13/07/2014, figura 6) é possível identificar os dois corpos de recifes, classificados inicialmente por Branner (1904), um mais interno e outro mais externo ao continente, sob influência da maré.

$\mathrm{Na}$ figura $6 \mathrm{~b}$ não é possível verificar a continuidade do recife interior, mesmo em baixa-mar, devido à cobertura sedimentar recente.

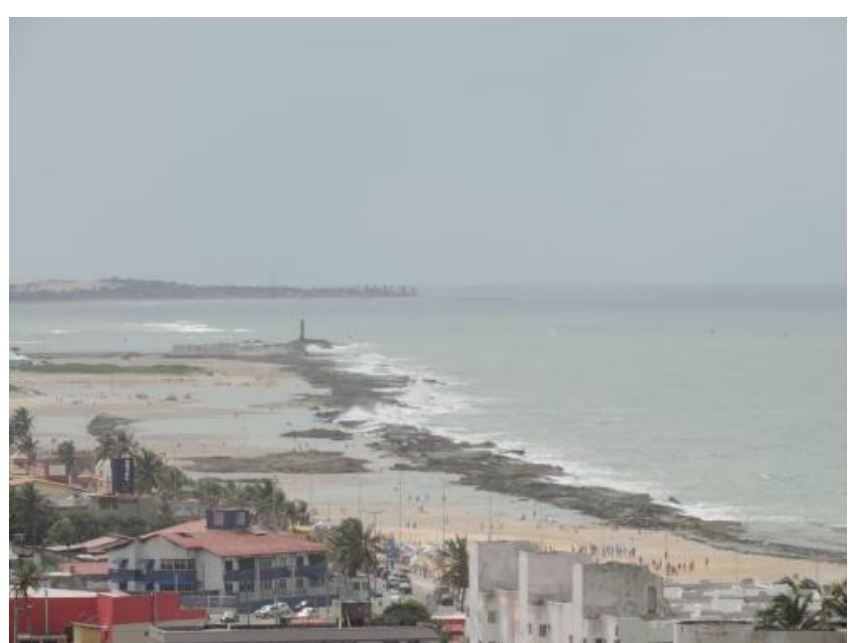

Figura 6 - Comparativo de imagens com os corpos de arenitos sob preamar (a) e baixamar (b). Fotos: Matheus Lisboa ( $\mathrm{a}-11 / 07 / 2014$ às $14 \mathrm{~h} 36 ; \mathrm{b}-13 / 07 / 2014$ às $12 \mathrm{~h} 28)$.

Geologicamente estes corpos de arenitos compõem a unidade N4ra na Folha Natal (SB.25-V-C-V), sendo descritas como "Recifes arenosos: arenitos com cimentação carbonática com bioclastos, granulometria média a grossa, distribuídos como linhas de recifes 
paralelamente à costa atual" (Fonseca et al. 2012). Oliveira et al. (1990) reconheceram as duas linhas de recifes (descritos por eles como beachrocks) que margeiam o litoral oriental norteriograndense e, por meio de datação pelo método ${ }^{14} \mathrm{C}$, propuseram idade média de 6250 anos A.P. para o recife mais próximo do continente (interno, segundo Branner, 1904), e de 4700 anos A.P. para o mais afastado do continente (externo, segundo Branner, 1904). Para eles, a zona de estirâncio (faixa do litoral ligeiramente inclinada para o mar e situada entre os níveis médios das marés baixa e alta) seria o local mais provável para a formação dessas rochas.

As rochas que compõem os recifes se relacionam com a cidade não somente por serem objetos da paisagem, mas por também terem uso no erguimento de seu espaço físico, como apresentou Dantas (2001). Segundo esse autor as rochas dos recifes da foz do Rio
Potengi foram extraídas e lavradas em blocos com os quais foi edificado o Forte dos Reis Magos.

Esse mesmo tipo de rocha pode ainda ser identificado nas igrejas de Nossa Senhora da Apresentação, de Santo Antônio e do Rosário, aplicado em soleiras, colunas e demais usos, apresentando fino acabamento, indicando a persistência de uma cantaria até o início do século XIX. Carvalho (2010) e Nascimento \& Carvalho (2013) reforçaram essa atestação apresentando o uso desse tipo de rocha (descritas então como arenitos calcíferos) compondo a arquitetura na forma de cantarias utilizadas para emoldurar os vãos e detalhes construtivos das igrejas setecentistas.

Fica claro na literatura e na história de Natal que as rochas disponíveis na região foram matérias para a evolução do povoado à cidade, favorecendo-se da disponibilidade e do prático uso de tais litotipos.

\section{AS ROCHAS NO FORTE DOS REIS MAGOS}

Durante os estudos arqueológicos no Forte dos Reis Magos foram obtidas quatro amostras

encontradas na base de trincheiras abertas em diferentes compartimentos do Forte (Figura 7).

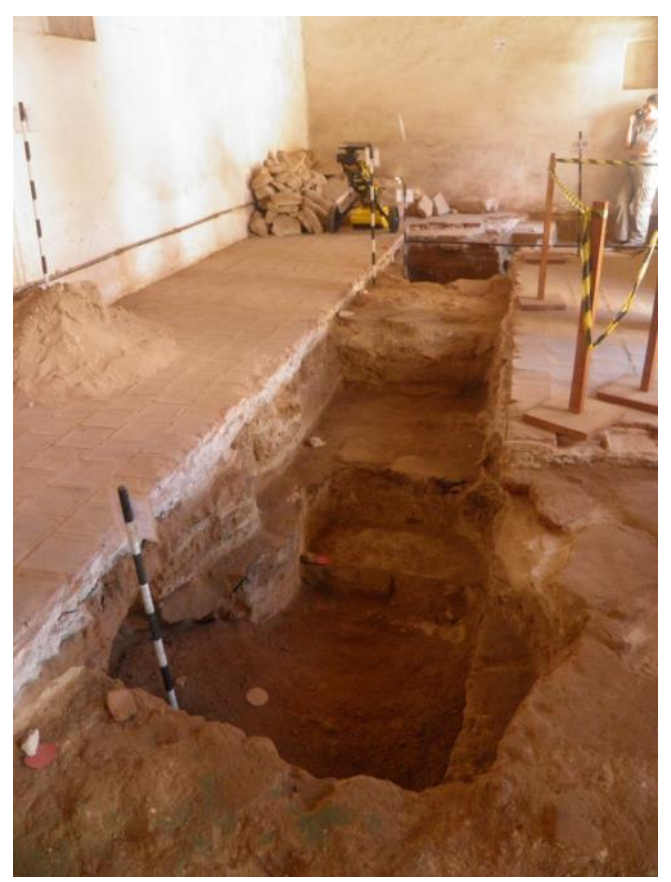

Figura 7 - Trincheira aberta em um dos compartimentos do Forte dos Reis Magos mostrando diferentes níveis (pisos) durante os estudos arqueológicos, aonde foram coletadas as amostras analisadas. Foto: Marcos Nascimento.

As amostras FRM-1, FRM-2, FRM-3 e FRM4, assim denominadas, passaram in loco por estudos envolvendo descrição macroscópica com apoio de lupa de mão, onde foi possível identificar sua mineralogia, textura e reação a ácido $(\mathrm{HCl})$. Lâminas delgadas confeccionadas a partir destas amostras foram descritas ao microscópio petrográfico.

\section{Descrição Petrográfica}

Em geral as amostras possuem as mesmas características (figura 8), apresentando cor clara (cinza clara a creme), granulometria variando de 
fina a média, compostas principalmente por grãos de quartzo angulosos a subarredondados, raros minerais escuros (evidente apenas na amostra FRM-4, o que oferece uma cor mais avermelhada a rocha) e bioclastos (resquícios de conchas marinhas). Mostram-se maciça ou com estratificação cruzada e possuem cimento de carbonato de cálcio evidenciado pela reação ao ataque de $\mathrm{HCl}$ (ácido clorídrico a 10\%).
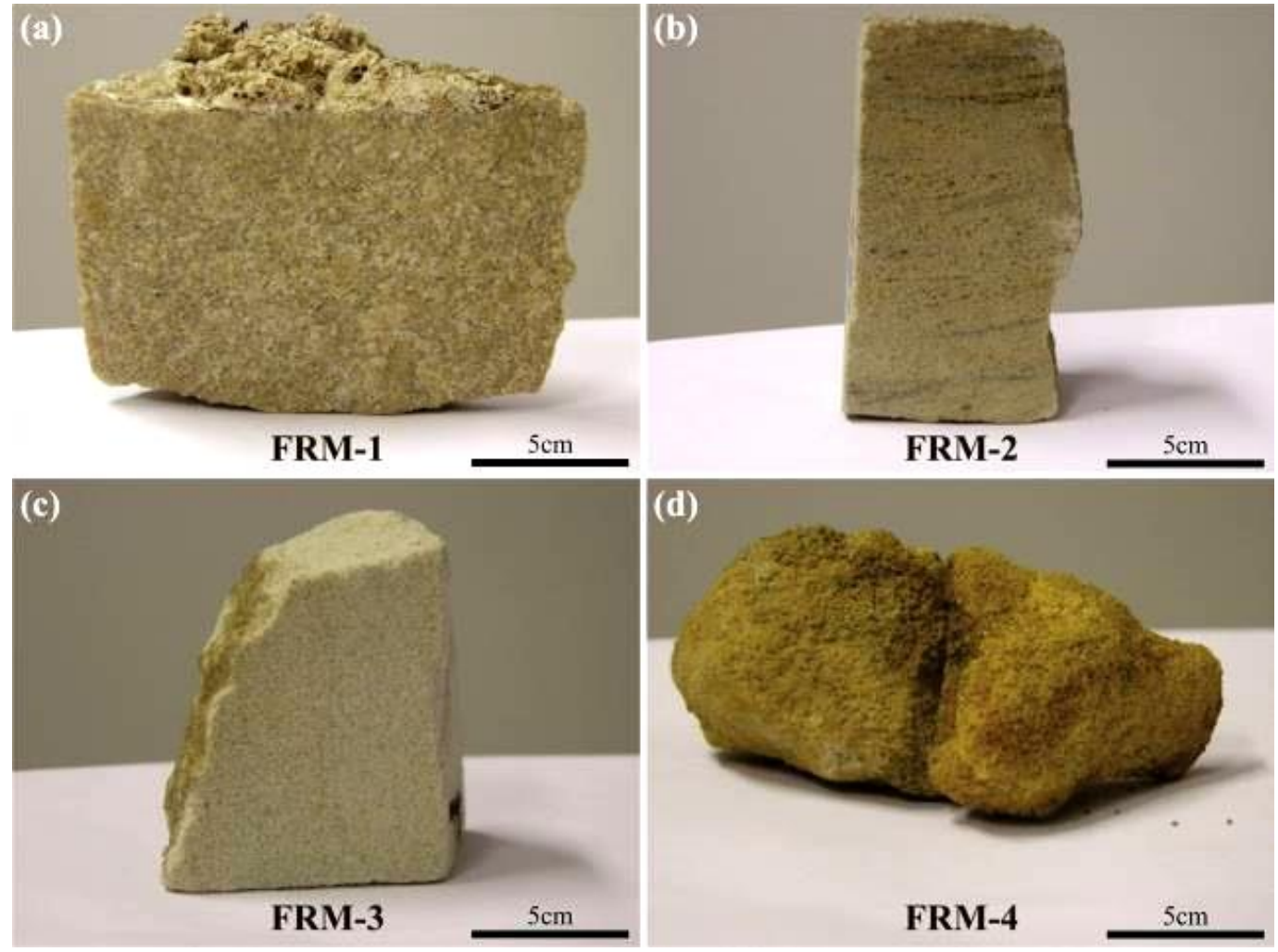

Figura 8 - Amostras coletadas em escavações arqueológicas realizadas no Forte dos Reis Magos. (a) Amostra FRM-1, de aspecto maciço, com construção biótica na porção superior, representada por restos de ostras. (b) Amostra FRM-2, de aspecto laminar, mostrando estratificação cruzada. (c) Amostra FRM-3, de aspecto maciço, cor clara e parcialmente friável. (d) Amostra FRM-4, intensamente friável, de cor amarelada. Fotos: Marcos Nascimento.

Essas características citadas anteriormente são muito semelhantes às encontradas em rochas dos recifes que ocorrem nas imediações do Forte dos Reis Magos, em posição original (figura 9), fixadas ao redor do referido monumento (figura 10) ou mesmo no seu pórtico de entrada (figura
11). Também é possível encontrar blocos de arenitos compondo as paredes internas do monumento histórico, contudo diversas modificações feitas ao longo dos anos descaracterizaram-nas.

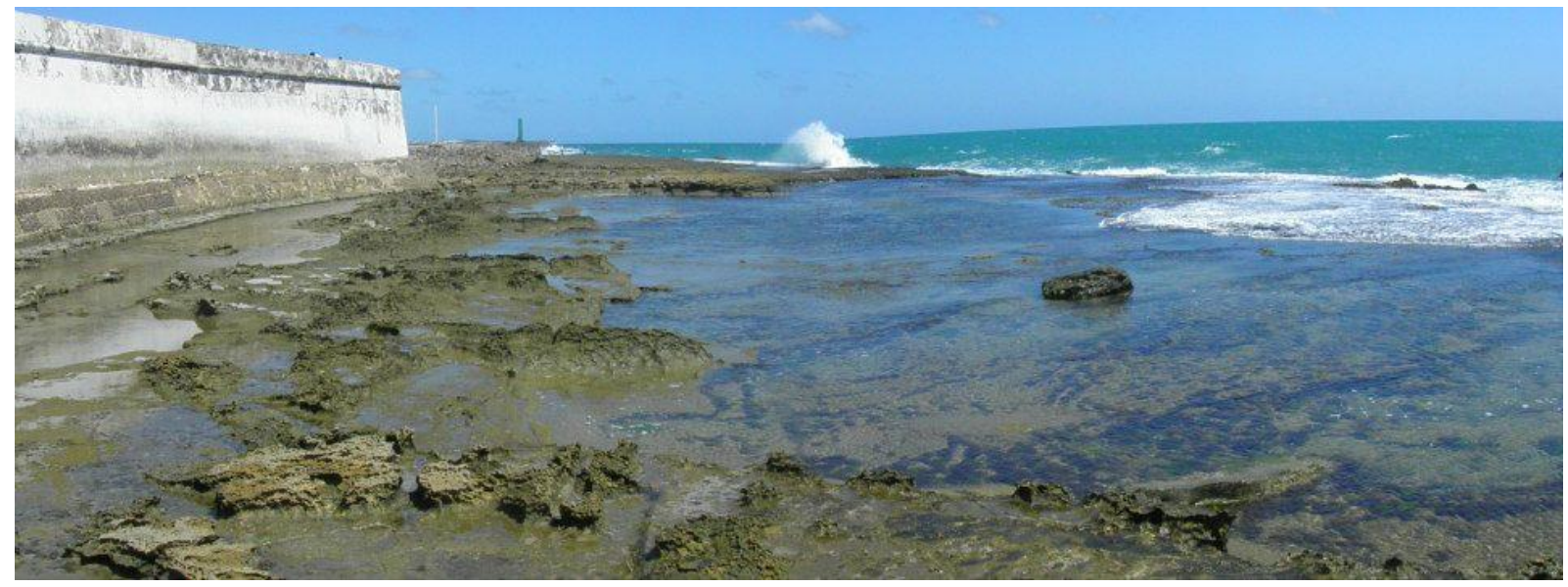

Figura 9 - Recife encontrado na lateral do Forte dos Reis Magos, descrito por Branner (1904) como "externo" formado por rochas semelhantes às descritas na base da fortificação. Foto: Marcos Nascimento. 


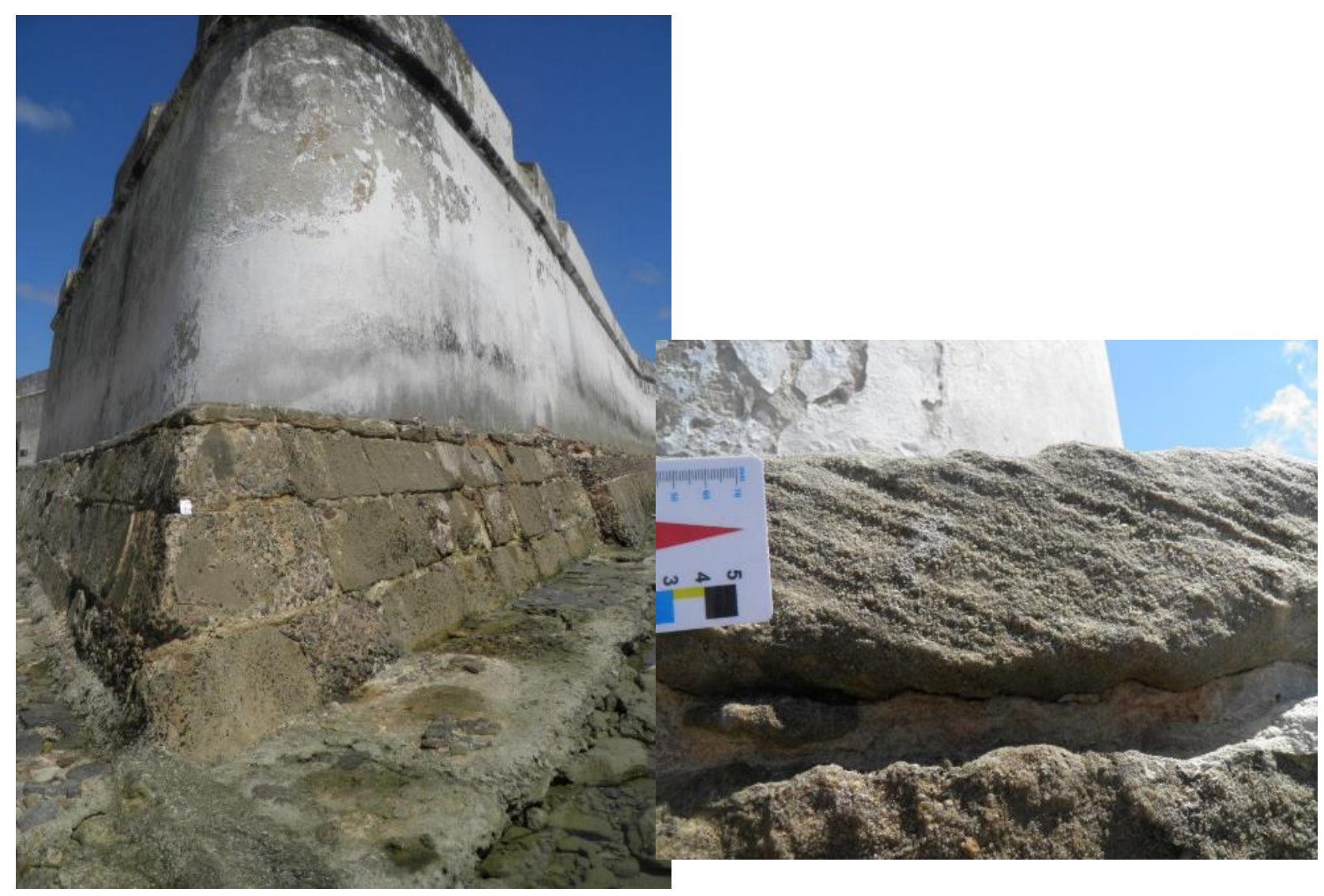

Figura 10 - Blocos de arenitos provenientes dos recifes utilizados para compor a fortificação (à esquerda). Em detalhe (acima) bloco de arenito com estratificação cruzada e granulometria fina a média. Fotos: Marcos Nascimento.

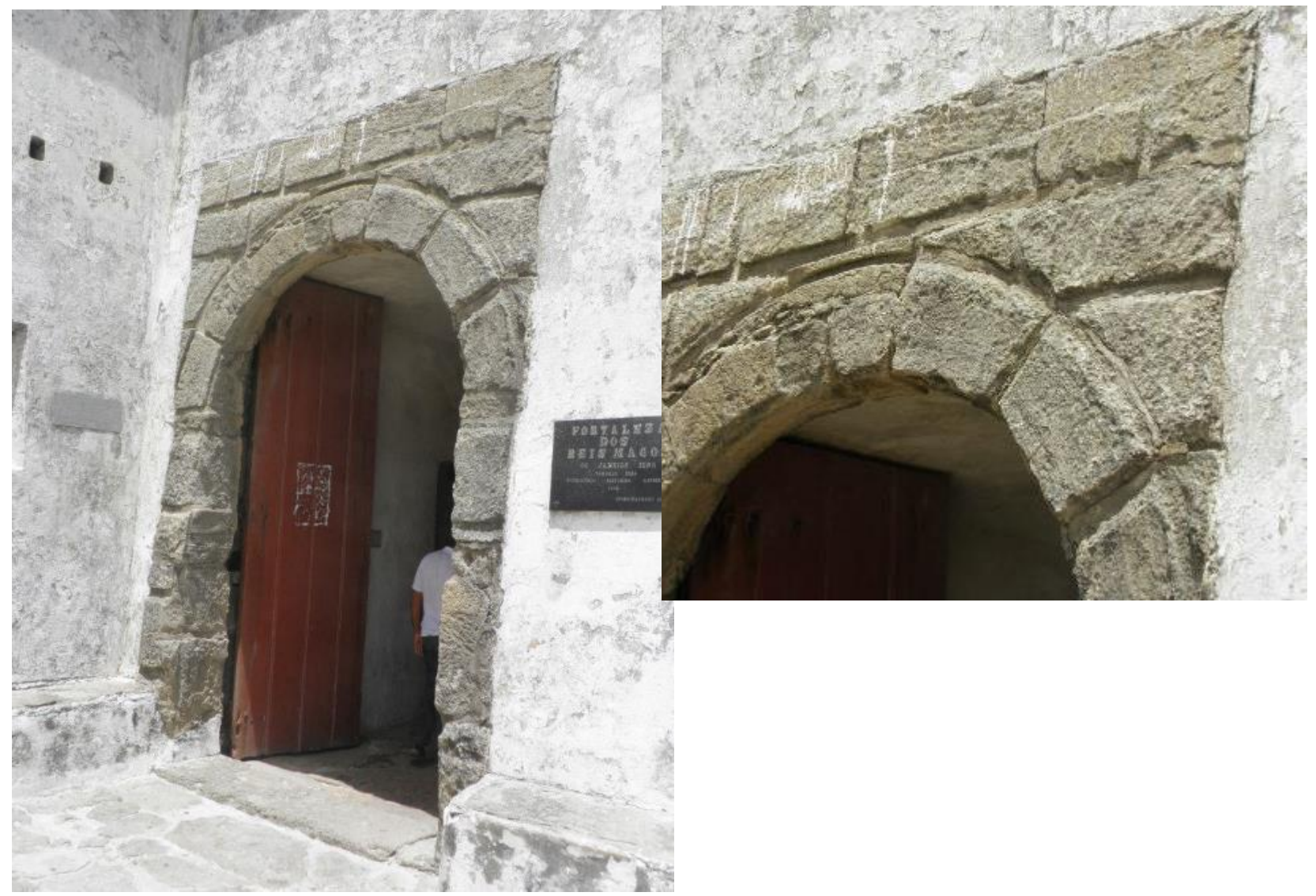

Figura 11 - Pórtico de entrada do Forte dos Reis Magos erguido com blocos de arenitos retirados dos recifes (à esquerda). Detalhe da porção superior do pórtico (acima) com alguns blocos mostrando estratificação na rocha. Fotos: Marcos Nascimento. 
As descrições ao microscópio petrográfico mostraram que as rochas utilizadas no Forte dos Reis Magos, tanto na fundação da estrutura como em sua ornamentação, se tratam de arcósio (FRM-1), subarcósio (FRM-2) e quartzoarenitos (FRM-3 e FRM-4), submaduros a maduros com cimentação carbonática em todas as amostras. A amostra FRM-4 ainda apresenta uma cimentação por óxidos. São predominantes no arcabouço das amostras descritas a presença de quartzo monocristalino (constituído por um único cristal), plagioclásio e microclínio (Figura 12A). Ocorrem de forma secundária bioclastos, apatita, turmalina, epidoto (Figura 12B), muscovita, titanita, biotita e intraclastos.

Os componentes aloquímicos presentes são fragmentos de algas vermelhas (Figura 13A) e oólitos (Figura 13B).
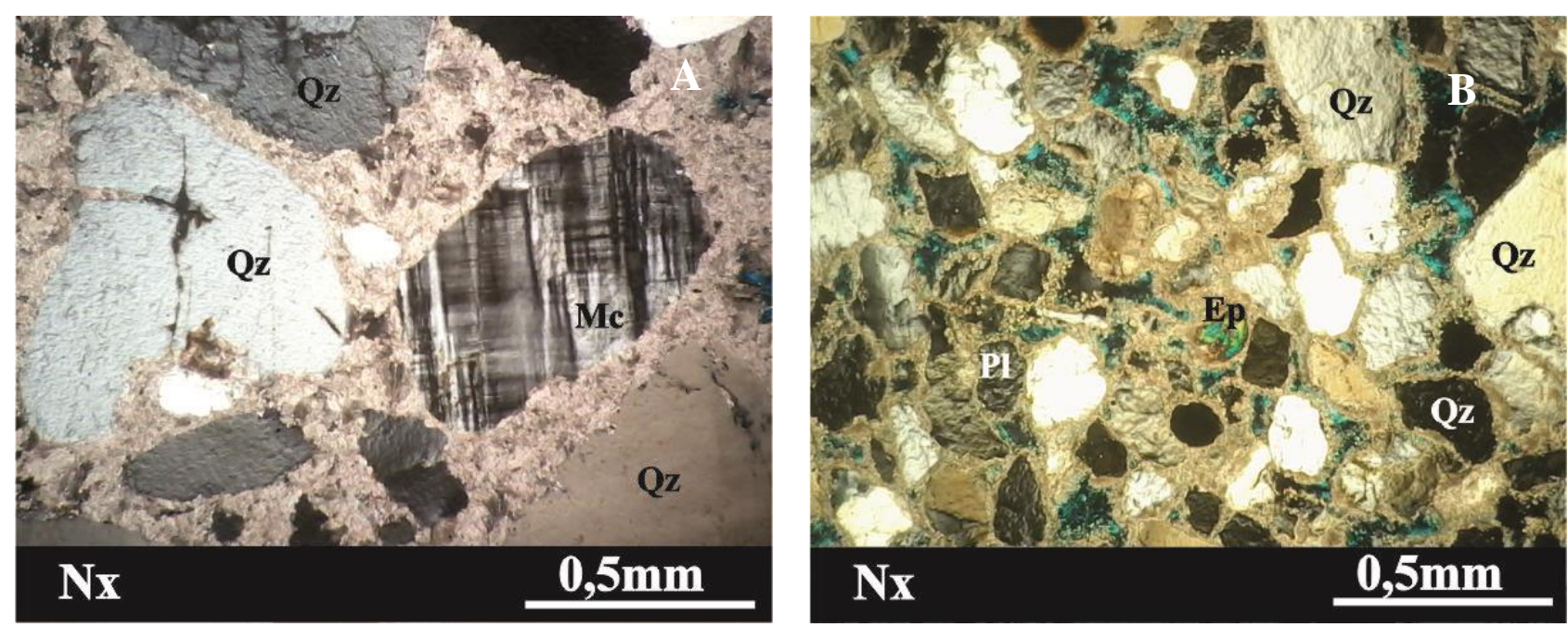

Figura 12 - A) Fotomicrografia da amostra FRM-1, com nicóis cruzados, mostrando grãos de microclínio (Mc), quartzo (Qz) e cimento (seta vermelha) em mosaico, formado por microcristais carbonáticos. B) Fotomicrografia da amostra FRM-2, com nicóis cruzados, mostrando grãos de quartzo $(\mathrm{Qz})$, plagioclásio $(\mathrm{Pl})$ e epidoto $(\mathrm{Ep})$.
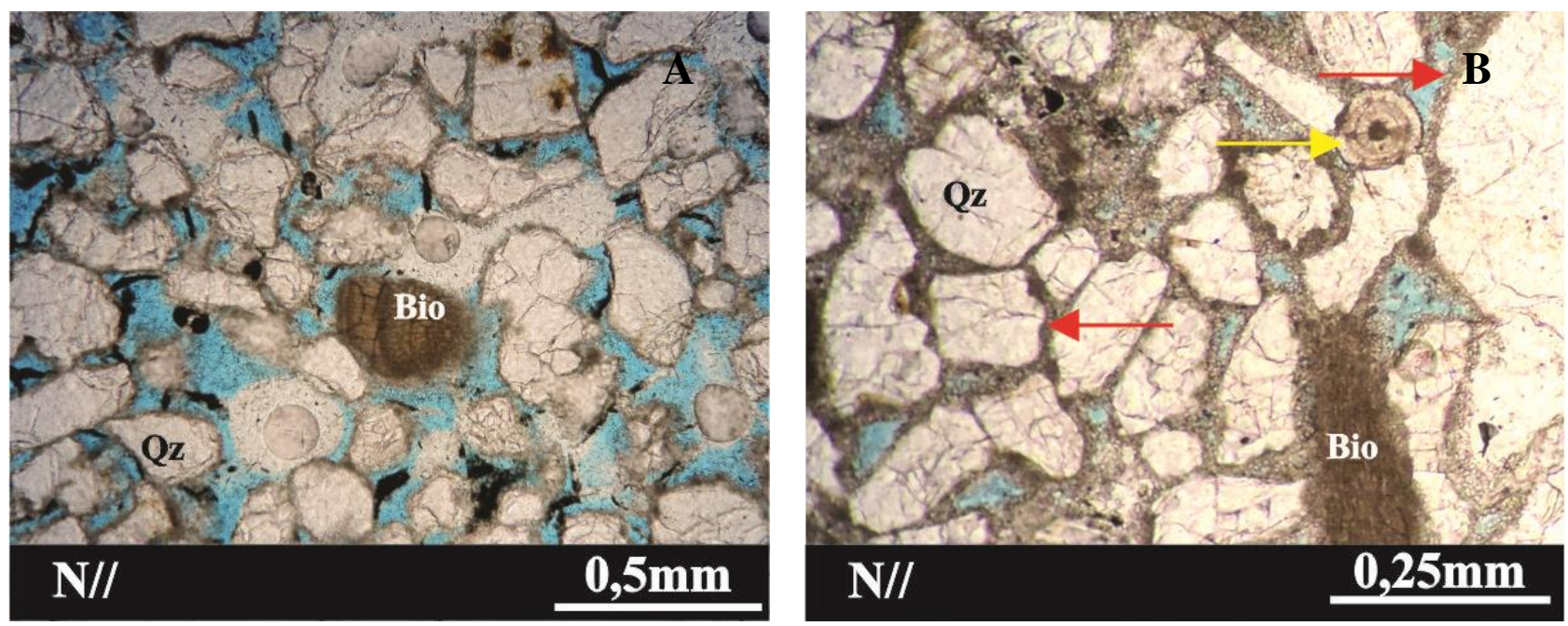

Figura 13 - A) Fotomicrografia da amostra FRM-3, com nicóis paralelos, mostrando fragmento de alga vermelha (Bio) e grãos de quartzo (Qz), e em azul a porosidade intergranular. B) Fotomicrografia da amostra FRM-2, com nicóis paralelos, mostrando grãos de quartzo $(\mathrm{Qz})$, bioclasto (Bio) e oólito (seta amarela), além do cimento em franjas isópacas (seta vermelha). Em azul, porosidade intergranular.

O cimento carbonático é composto por cutículas com textura criptocristalina e microcristalina, além de franjas fibrosas e cristais fibro-radiais ao redor dos grãos do arcabouço, atingindo $0,3 \mathrm{~mm}$. Localmente, o cimento carbonático chega a substituir parcialmente os grãos e por vezes penetra nas fraturas dos mesmos, como é mostrado na figura 16.

Especificamente na amostra FRM-4, ocorrem níveis de cimento provavelmente ferruginoso que preenchem fraturas (Figura $14 \mathrm{~B}$ ), o que dá à rocha uma coloração amarelada. Contudo, mesmo 
nesta amostra, a cimentação é, predominante, carbonática.

A porosidade predominante nas amostras descritas é do tipo intergranular primária e apresenta-se, por vezes, parcial a totalmente

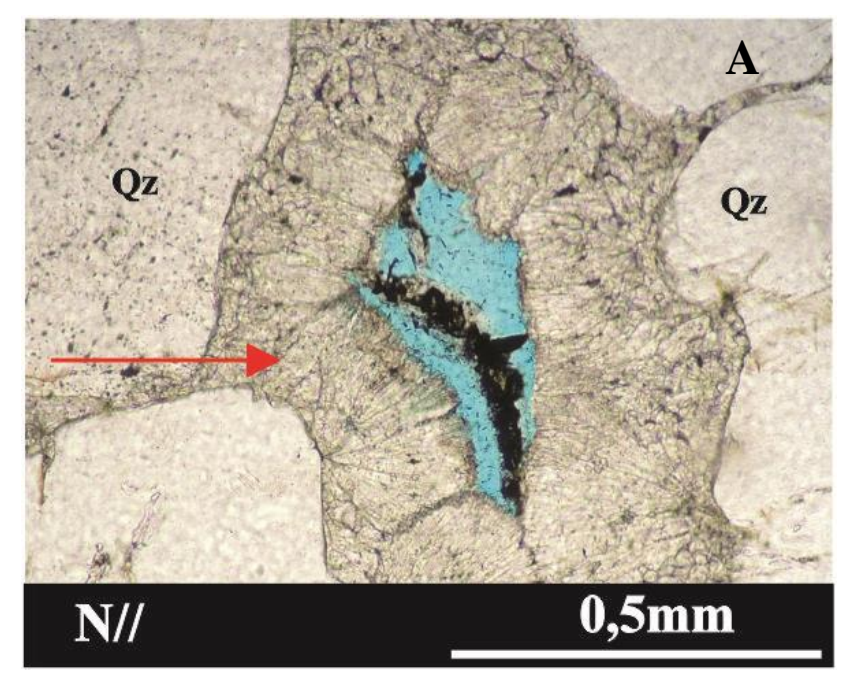

preenchida pelos cristais carbonáticos, responsáveis pela cimentação dos arenitos. Quando os poros são totalmente preenchidos pelo cimento carbonático passa a ser observada uma textura de cimento em mosaico.

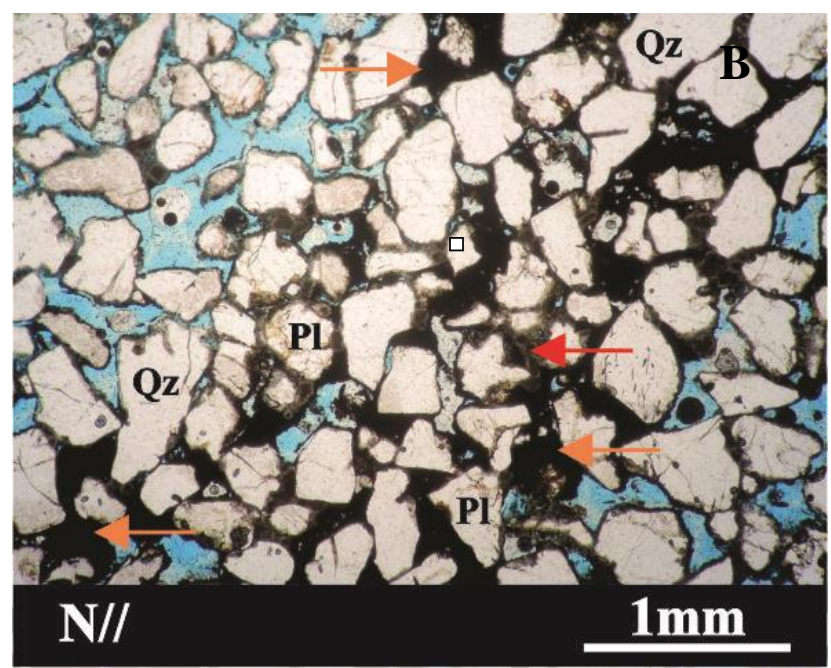

Figura 14 - A) Fotomicrografia com nicóis paralelos da amostra FRM-1, mostrando cimento carbonático (seta vermelha) em franja fibro-radial preenchendo porosidade primária, além dos grãos quartzosos (Qz) do arcabouço. B) Fotomicrografia com nicóis paralelos da amostra FRM-4, indicando, com as setas na cor laranja, o cimento de mineral opaco e mostrando grãos de quartzo $(\mathrm{Qz})$ e plagioclásio $(\mathrm{Pl})$. Em azul, tem-se a porosidade intergranular, e a seta vermelha indica o cimento micrítico pseudopeloida.

De forma geral, a fábrica das amostras descritas apresenta um empacotamento frouxo, evidenciado pela predominância de grãos flutuantes e alguns contatos pontuais e retos. A exceção se dá com a amostra FRM-2 que apresenta um empacotamento normal, caracterizado por contatos retos e pontuais.

É possível correlacionar a origem geológica dos arenitos praiais da região de Natal, aonde se localiza o Forte dos Reis Magos, com algumas observações da literatura acerca do ambiente e processos de sedimentação nos quais foram originados os beachrocks.

Trabalhos de Barreto et al. (2004), Ferreira Jr. (2005) e Cabral Neto (2011) mostram que os arenitos praiais encontrados em todo o litoral do Nordeste brasileiro são registros de uma sedimentação ocorrida no Holoceno em zonas de intermaré a inframaré.

Corrobora com essa afirmação o trabalho de Vieira \& De Ros (2006), realizado no litoral setentrional do Rio Grande do Norte, que indicaram que a precipitação do cimento carbonático, de composição altamente magnesiana, ocorreu em zona ativa de saturação marinha e explicam que a rara ocorrência de estruturas orgânicas deriva do clima seco local, o que determina uma cimentação inorgânica.

\section{Diagênese}

Os processos diagenéticos que ocorreram nas amostras descritas são compactação mecânica, faturamento, precipitação de cimento carbonático e precipitação por cimento de minerais opacos, que não foram identificados pois não foi realizada análise química neste trabalho.

Com o soterramento raso, houve a compactação mecânica, provocando uma diminuição dos espaços vazios, pelo rearranjo dos grãos, em uma profundidade saturada por água do mar.

Esta, por sua vez, ocasionou a precipitação do cimento carbonático em franja, característico deste ambiente, que na amostra FRM-01 é mais intensa do que nas outras amostras.

Por ser uma cimentação relativamente precoce, o processo de compactação foi interrompido, resultando em um empacotamento frouxo. Com o avanço da precipitação, alguns grãos do arcabouço arenoso foram parcialmente substituídos pelo cimento carbonático e tiveram seu arredondamento modificado.

A fratura observada na amostra FRM-04 ocorreu provavelmente num momento de ascensão à superfície por descompressão do arenito, e foi preenchida por cimento de minerais opacos, provavelmente de natureza ferrosa. 


\section{CONSIDERAÇÕES FINAIS}

É irrefutável a importância do Forte dos Reis Magos para a cidade de Natal, estando sempre presente no decorrer de sua história e sendo considerado um dos principais pontos históricoturístico da cidade.

A construção do monumento, contudo, só foi propiciado naquela localidade devido à existência dos recifes, formados por arenitos carbonáticos, representantes de antigas linhas de costa e que serviram de base sólida para a fortificação, além de fornecer material pétreo para a construção.

Os trabalhos arqueológicos realizados no local identificaram a presença de tais rochas na base e paredes da edificação e na ornamentação de pórticos, o que foi confirmado por estudos petrográficos (macro e microscópicos).

A partir da análise das quatro amostras obtidas, pode-se concluir que se tratam de quartzo arenitos e arenitos arcosianos, de maturidade textural variando de submaduros a maturos, havendo conteúdo aloquímico, com bioclastos e oólitos. Além disso, todas as amostras apresentaram cimentação carbonática, havendo uma amostra com precipitação de minerais opacos, preenchendo fraturas. A forte semelhança petrográfica (mineralogia, textura e reação ao ácido) entre essas rochas e àquelas que ocorrem na região, sob a forma de recifes, já apontavam para essa identificação, contudo estudos detalhados vieram corroborar tal fato.

Os resultados aqui apresentados podem embasar ações de proteção ao meio abiótico no local, em complementação a atividades de conservação da história local e de sua comunidade, uma vez que todo o conteúdo produzido pode ser utilizado na divulgação e popularização do conhecimento geológico à toda sociedade. As informações também podem ser empregadas com uso turístico, agregando valor e permitindo a popularização do conhecimento geológico. $\mathrm{Na}$ realidade fica claro que "as Rochas contam sua História"!

\section{AGRADECIMENTOS}

Os autores agradecem ao IPHAN-RN pela oportunidade de participar das pesquisas sobre o Forte dos Reis Magos, muito presente no cotidiano da cidade de Natal.

\section{REFERÊNCIAS}

BARRETO, A.M.F.; BEZERRA, F.H.R.; SUGUIO, K. Variações do nível do mar durante o Holoceno no Rio Grande do Norte, Brasil. In: SIMPÓSIO DE GEOLOGIA DO NORDESTE, 18, 2000, Recife Boletim de Resumos... Recife: Sociedade Brasileira de Geologia, p. 15-16.

BARRETO, A.M.F.; SUGUIO, K.; BEZERRA, F.H.R.; TATUMI, S.H.; YEE, M.; GIANNINI, P.C.F. Geologia e geomorfologia do Quaternário costeiro do estado do Rio Grande do Norte. Geologia USP - Série Científica, v. 4, n. 2, p. 1-12, 2004.

BRANNER, J.C. The stone reefs of Brazil, their geological and geographical relations, with a chapter on the coral reefs. Cambridge: Museum of Comparative Zoology at Havard College, 285 p., 1904.

BRANNER, J.C. \& GILMAN, C.E. O recife de pedra na foz do Rio Grande do Norte. Revista do Rio Grande do Norte, v. 2, n. 2, p. 35-41, 1900.

CABRAL NETO, I. Beachrocks do Rio Grande do Norte: correlação entre os depósitos costeiros e os de zona costaafora com base na faciologia, petrografia e diagênese. Natal, 2011. 144 p. Dissertação (Mestrado em Geodinâmica) - Departamento de Geologia, Universidade Federal do Rio Grande do Norte.

CARVALHO, H.L. Patrimônio geológico do centro histórico de Natal. Natal: Departamento de Geologia, 105 p., 2010.

CASCUDO, L.C. História da cidade do Natal. Natal: Editora Universitária da UFRN, 496 p., 1999.

DANTAS, E.R. Cantaria: arte no corte da pedra. Galante, v. 2, n. 5, p. 30-43, 2001.

DEL LAMA, E.A.; BACCI, D.L. C.; MARTINS, L.; GARCIA,
M.G.M.; DEHIRA, L.K.. Urban Geoturism and the Old Centre of São Paulo, Brazil. Geoheritage, v. 7, n. 2, p. 147-164, 2015.

FERREIRA JR, A.V. Mapeamento da zona costeira protegida por arenitos de praia (Beachrocks) em Nísia Floresta-RN. Natal, 2005. 105 p. Dissertação (Mestrado em Geodinâmica) - Departamento de Geologia, Universidade Federal do Rio Grande do Norte.

FERREIRA JÚNIOR, A.V.; ARAÚJO, T.C.M.; VIEIRA, M.M.; NEUMANN, V.H.; GREGÓRIO, M.N.. Petrologia dos Arenitos de Praia (Beachrocks) na Costa Central de Pernambuco. Geociências, v. 30, n. 4, p. 545-559, 2011

FONSECA, V.P.; SOUSA, M.O.L.; SILVA, F.O.; BEZERRA, F.H.R.; AMARAL, R.F.; SOUZA, Z.S.; FERREIRA, A.C.; DUTRA, R.R. Programa Geologia do Brasil - PGB Natal, Folha SB.25-V-C-V, Estado do Rio Grande do Norte, Carta Geológica. Natal: Companhia de Pesquisa de Recursos Minerais - Serviço Geológico do Brasil, escala $1: 100.000,2012$.

NASCIMENTO, M.A.L. \& CARVALHO, H.L. Geodiversidade no centro histórico de Natal/RN (NE do Brasil). In: SIMPÓSIO BRASILEIRO DE PATRIMÔNIO GEOLÓGICO, 2, 2013. Ouro Preto. Boletim de Resumos... Ouro Preto, 2013. CD-ROM.

NATAL, P.M. Zona de Proteção Ambiental 7, Forte dos Reis Magos e seu Entorno. Natal: Secretaria Municipal de Meio Ambiente e Urbanismo, 85 p., 2010.

OLIVEIRA, M.I.M. Os "Recifes" de Natal. Recife, 1978. 79 p. Dissertação (Mestrado em Geociências) - Programa de Pós-Graduação em Geociências, Universidade Federal de Pernambuco. 
OLIVEIRA, M.I.M.; BAGNOLI, E.; FARIAS, C.C.; NOGUEIRA, A.M.B.; SANTIAGO, M. Considerações sobre a geometria, petrografia, sedimentologia, diagênese e idades dos beachrocks do Rio Grande do Norte. In: CONGRESSO BRASILEIRO DE GEOLOGIA, 36, 1990, Natal. Boletim de Resumos... Natal: Sociedade Brasileira de Geologia, 1990, p. 621-634.
VIEIRA, M.M. \& DE ROS, L.F. Cementation patterns and genetic implications of Holocene beachrocks from northeastern Brazil. Sedimentary Geology, v. 192, p. 207230, 2006.

Submetido em 14 de abril de 2016 Aceito em 20 de dezembro de 2016 